\title{
An evidence-based overview of hybridization in tinamous
}

\author{
Jente Ottenburghs ${ }^{1,2}$ (D) \\ Received: 2 March 2021 / Revised: 11 May 2021 / Accepted: 12 May 2021 / Published online: 20 May 2021 \\ (C) The Author(s) 2021
}

\begin{abstract}
Estimates suggest that about $16 \%$ of bird species hybridize in the wild. This number is based on two main sources: the Handbook of Avian Hybrids of the World by Eugene McCarthy and the online Serge Dumont Bird Hybrids Database. Although both sources provide supporting references for the documented hybrids, the reliability of these references has not been systematically assessed. In this paper, I introduce a scoring scheme based on three criteria that are weighted based on their reliability, namely field observations or photographs (1 point), morphological analyses ( 2 points), and genetic analyses ( 3 points). The final tally of these three criteria (ranging from 0 to 6 points) will indicate the level of confidence for a particular hybrid. I test this scoring scheme on the Neotropical bird family Tinamidae (tinamous), in which several putative hybrids have been reported. My analysis revealed one welldocumented case (Crypturellus boucardi $\times$ C. cinnamomeus) and three doubtful records that require further investigation. These findings highlight the need for thoroughly scrutinizing the sources supporting avian hybrids. The scoring system clearly illustrates its usefulness and can be easily applied to other taxonomic groups to increase the reliability of documenting interspecific hybrids.
\end{abstract}

Keywords Citizen science $\cdot$ Hybridization $\cdot$ Introgression $\cdot$ Morphology $\cdot$ Tinamidae

\section{Introduction}

Hybridization refers to the situation where species "that are distinguishable on the basis of one or more heritable characters overlap spatially and temporally and cross to form viable and at least partially fertile offspring" (Arnold 1997). Although this phenomenon is rare on an individual level, hybrids between numerous bird species have been documented (Justyn et al. 2020; Ottenburghs and Slager 2020). Indeed, according to the latest estimates, about $16 \%$ of bird species has hybridized with another species (Ottenburghs et al. 2015). This percentage is primarily based on two sources: the Handbook of Avian Hybrids of the World (McCarthy 2006) and the online Serge Dumont Bird Hybrids Database (Dumont n.d.). Both sources provide abundant references for the reported hybrids, but the reliability of these references has generally been taken at face value.

Communicated by Alexandre Aleixo

Jente Ottenburghs

jente.ottenburghs@hotmail.com

1 Wildlife Ecology and Conservation, Wageningen University \& Research, Wageningen, the Netherlands

2 Forest Ecology and Forest Management, Wageningen University \& Research, Wageningen, the Netherlands
Identifying hybrids can be especially difficult for morphologically similar species and cryptic species that are rarely observed (Randler 2004). After detailed analyses some putative hybrids turn out to be individuals with aberrant plumage patterns. For example, genetic analyses indicated that a presumed hybrid between Red-tailed Hawk (Buteo jamaicensis calurus) and Redshouldered Hawk (B. j. elegans) in California, USA, was probably an atypical Red-shouldered Hawk from an eastern population (Clark et al. 2017). It is thus important to carefully assess the evidence for and against the hybrid origin of a bird.

To determine the reliability of the data sources supporting hybrid records, I introduce a scoring scheme based on three criteria.

\section{Methods}

The proposed scoring scheme is based on (1) the observation of a putative hybrid with photographic evidence or a detailed description, (2) thorough morphological analyses in which the putative hybrid is compared with potential parental species, and (3) genetic analyses of the putative hybrid with reference material from potential parental species.

The first criterion encompasses sightings in online databases, such as eBird (Sullivan et al. 2009), as well as scientific 
papers describing the observation of a presumed hybrid. For example, Haines (2014) reported a putative hybrid between Splendid Fairywren (Malurus splendens) and White-winged Fairywren (M. leucopterus) in Australia based on photographic evidence. The second criterion requires analyses in which the hybrid specimen is quantitatively and/or qualitatively compared with the probable parental species. For instance, Apolinario and Silveira (2019) compared the plumage patterns of several museum specimens to identify hybrids between the Plush-crested Jay (Cyanocorax chrysops) and the White-naped Jay (C. cynanopogon) in Brazil. The third criterion includes genetic analyses that confirm the hybrid origin of an individual (Knowlton et al. 2014; Toews et al. 2020) or document recent gene flow between interbreeding species (Coster et al. 2018; Maxwell et al. 2021).

To express the varying levels of confidence that each of these criteria provide, they will be weight differently in the final score for a putative hybrid, namely one point for an observation, two for a morphological analysis, and three for a genetic test. The final tally of these three criteria (ranging from 0 to 6 points) will indicate the level of confidence for a particular hybrid combination. It is important to note that this scoring scheme does not directly assess the reliability of the supporting evidence but rather provides an overview of the different observational, morphological, or genetic studies that accompany a particular hybrid record. If the data in a certain criterion are unreliable or uncertain, a question mark (?) can be added to the overview.

In addition to this scoring scheme, one should take into account additional sources of information, such as the distribution of the parental species and their divergence time. If the putative parental species do not overlap in distribution, the hybrid record can be considered less reliable (although one has to consider escaped or introduced individuals). Similarly, an extremely old divergence time between the parental species can cast doubt on a proposed hybrid. It has been estimated that bird species lose the ability to hybridize after an average of ca. 21 million years of evolution (Fitzpatrick 2004). Extreme cases have been reported, such as a cross between Helmeted Guineafowl (Numida meleagris) and Domestic Chicken (Gallus gallus), two species that diverged about 55 million years ago (Price and Bouvier 2002). However, such exceptional cases between distantly related species require convincing evidence to be considered reliable.

In this paper, I will apply the scoring scheme on the Tinamidae (tinamous), a Neotropical family of cryptic birds. Although some tinamou hybrids are known from captivity, I will focus on records of potential hybrids in the wild. In captivity, the hybrids and their parental species are mostly obvious and do not require detailed morphological or genetic analyses that form the basis of the introduced scoring system. However, captive hybrids can provide comparative material when assessing potential hybrids in the wild. I will thus restrict the application of the scoring system to wild hybrids that have been reported in the scientific literature.

\section{Results}

\section{Putative tinamou hybrids}

Based on the Handbook of Avian Hybrids of the World (McCarthy 2006) and the Serge Dumont Bird Hybrids Database (Dumont n.d.), I found four records of putative tinamou hybrids that warrant further investigation (Table 1). Additional searches on Web of Science and Google Scholar did not uncover other hybrids. In addition to these four cases, McCarthy (2006) also mentioned a parapatric contact zone between Brown Tinamou (C. obsoletus) and Traylor's Tinamou (C. traylori, now considered a subspecies of C. obsoletus) in Peru, but he noted that no hybrids have been reported. And there might have been a captive cross involving the Tataupa Tinamou (C. tataupa) in the Olmense Zoo (Belgium), but the other parental species was not specified. In the following sections, I will discuss the evidence supporting the four presumed hybrids by applying the scoring scheme described above. Moreover, I will check whether the parental species overlap in distribution (using data from BirdLife International) and whether the divergence time between the parental species is realistic.

\section{Crypturellus boucardi $\times$ cinnamomeus}

In the Handbook of Avian Hybrids of the World, McCarthy (2006) mentioned one well-documented case of hybridization in tinamous, namely Slaty-breasted Tinamou (Crypturellus boucardi) and Thicket Tinamou (C. cinnamomeus) which interbreed in Honduras. Two hybrid specimens were briefly described in Monroe Jr. (1965).

Hybridization between $C$. boucardi and C. cinnamomeus occurs occasionally as evidenced by the two specimens cited above, both collected in 1937 by C. F. Underwood. They are morphologically intermediate between the two species, resembling cinnamomeus in general aspect but being much darker above and below, especially on the breast, and having the light bars on the wing coverts more tawny, as in boucardi. Apparently the isolating mechanisms (perhaps call notes in this case) are not completely effective in areas of contact, such as the Catacamas region where rain forest borders on arid scrub and cultivated lands. In most of the range of the two species, however, the difference in habitat preference prevents their contact. 
Table 1 Evidence for putative hybrids in the family Tinamidae, including geographical overlap in distribution and estimated divergence times

\begin{tabular}{|c|c|c|c|c|c|c|c|}
\hline Species 1 & Species 2 & $\begin{array}{l}\text { Geographical } \\
\text { Overlap }\end{array}$ & $\begin{array}{l}\text { Divergence } \\
\text { Time }\end{array}$ & Observation & Morphology & Genetics & Verdict \\
\hline $\begin{array}{l}\text { Slaty-breasted Tinamou } \\
\text { Crypturellus boucardi }\end{array}$ & $\begin{array}{l}\text { Thicket Tinamou } \\
\text { Crypturellus cinnamomeus }\end{array}$ & YES & $<17$ MYA & 1 & 2 & 0 & 3 \\
\hline $\begin{array}{l}\text { Elegant Crested Tinamou } \\
\text { Eudromia elegans }\end{array}$ & $\begin{array}{l}\text { Quebracho Crested Tinamou } \\
\text { Eudromia formosa }\end{array}$ & YES & $<17$ MYA & $?$ & 0 & 0 & 0 \\
\hline $\begin{array}{l}\text { White-bellied Nothura } \\
\text { Nothura boraquira }\end{array}$ & $\begin{array}{l}\text { Brushland Tinamou } \\
\text { Nothoprocta cinerascens }\end{array}$ & YES & $<17$ MYA & $?$ & 0 & 0 & 0 \\
\hline $\begin{array}{l}\text { Huayco Tinamou } \\
\text { Rhynchotus maculicollis }\end{array}$ & $\begin{array}{l}\text { Red-winged Tinamou } \\
\text { Rhynchotus rufescens }\end{array}$ & NO & $<17$ MYA & $?$ & 0 & 0 & 0 \\
\hline
\end{tabular}

The statement that these species interbreed in Honduras is supported by the current distribution maps (Fig. 1A). Interestingly, morphological and genetic analyses suggest that Slaty-breasted Tinamou and Thicket Tinamou are not sister species (Bertelli and Porzecanski 2004; Bertelli et al. 2014; Bertelli 2017). Their divergence time remains uncertain but is probably less than 17 million years ago when the two main tinamou subfamilies (Nothurinae and Tinaminae) likely originated. There is, however, no genetic data supporting this hybrid combination. It would be interesting to genotype the two hybrid specimens mentioned by Monroe Jr. (1965) and provide an additional piece of evidence.

\section{Eudromia elegans $\times$ formosa}

In his zoogeographic analysis of the South American Chaco avifauna, Short (1975, p. 192) suggested that Elegant Crested Tinamou (Eudromia elegans) and Quebracho Crested
Tinamou (E. formosa) may be in contact but indicated that their interactions are unknown. Their current distributions do indeed overlap (Fig. 1B), but no hybrids have been reported. In addition, recent phylogenetic studies based on morphological (Bertelli et al. 2002) and genetic (Bertelli and Porzecanski 2004) data indicated that both species are clearly distinct. More research is thus needed to assess the reliability of hybridization between Elegant Crested Tinamou and Quebracho Crested Tinamou.

\section{Nothura boraquira $\times$ Nothoprocta cinerascens}

Short (1976, p. 2) discussed the morphological resemblance between White-bellied Nothura (Nothura boraquira) and Brushland Tinamou (Nothoprocta cinerascens), but offered no clear evidence for hybridization. He wrote that "the rather weak differentiation of Chaco marmorata [i.e. a subspecies of Nothoprocta cinerascens] implies a recent contact with

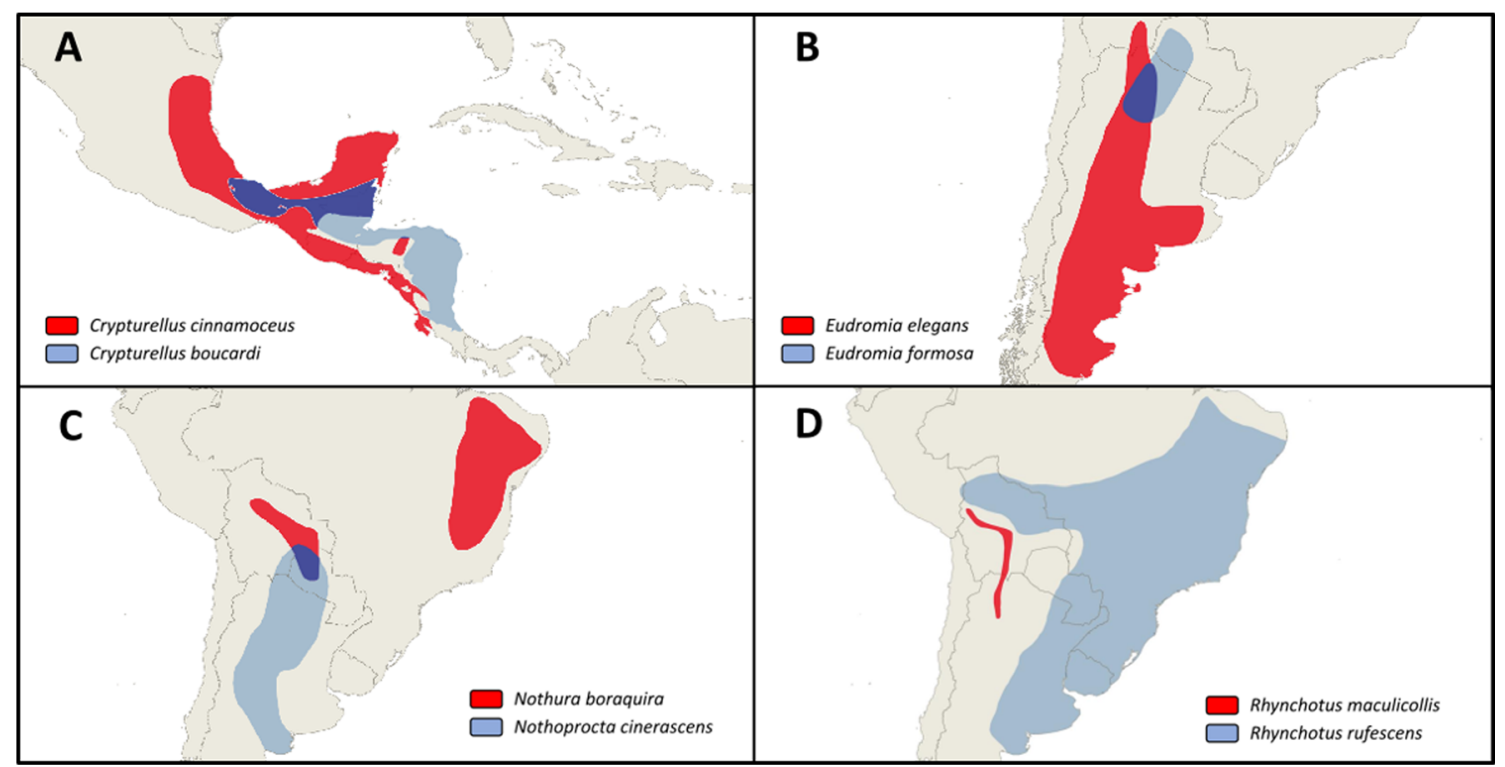

Fig. 1 Distribution maps of putative parental species for four hybrid combinations: (A) Crypturellus cinnamoceus x boucardi, (B) Eudromia elegans x formosa, (C) Nothura boraquira $x$ Nothoprocta cinerascens, and (D) Rhynchotus maculicollis $x$ rufescens. The distribution of the two species is indicated in red or light blue, while regions of overlap are highlighted in dark blue. Based on data from BirdLife International and Handbook of the Birds of the World (2020) 
Caatinga boraquira." Both species overlap in Bolivia and Paraguay (Fig. 1C), but no hybrids are known.

\section{Rhynchotus rufescens $\times$ maculicollis}

Finally, when describing the distribution of the Red-winged Tinamou (Rhynchotus rufescens), Short (1975, p. 189) mentioned that the subspecies pallescens seems to intergrade with two other subspecies (rufescens and maculicollis). The latter one has recently been elevated to species rank based on a distinctive song (Maijer 1996). However, these species do not seem to overlap in distribution (Fig. 1D) and occur on different elevation levels (Maijer 1996). Moreover, hybridization has not been reported by additional studies.

\section{Discussion}

Checking the reliability of the sources supporting several putative tinamou hybrids revealed one well-documented case and three doubtful records. Hybridization between Slatybreasted Tinamou and Thicket Tinamou is clearly reported by Monroe Jr. (1965) with a concise morphological description of two hybrid specimens. However, genetic confirmation is currently missing (Table 1). A genetic analysis of these specimens or a population genetic study of both species might provide an additional piece of evidence to remove all doubt. The three other putative hybrids can be traced back to the work of Short $(1975,1976)$. Careful reading of his monographs showed that these hybrid records are based on anecdotes and speculation about potential interbreeding in overlapping ranges. Although the distributional data confirm geographical overlap in two cases, the possibility of hybridization is mainly hypothetical and not supported by additional studies. Hence, I cannot assign any points to them in the scoring system (Table 1). These putative hybrids require further investigation, preferably with genetic techniques.

My assessment of tinamou hybrids also highlights the lack of genetic data in this bird group. There are some genetic studies on tinamou populations (Bertelli and Porzecanski 2004; Deck et al. 2016), but few have looked into phylogenetic relationships and potential hybridization. I could not find precise divergence times for the species pairs and had to rely on a maximum date that corresponds to the split between the subfamilies Nothurinae and Tinaminae (17 million years ago, Bertelli 2017). This date is within the range of divergence times at which bird species still have the ability to hybridize (on average 21 million years, Fitzpatrick 2004), but more precise divergence times are needed to determine the reliability of these hybrids and assess the possibility of introgression. The advent of genomic data offers exciting opportunities to investigate whether there has been recent or ancient introgression between certain tinamou species (Ottenburghs et al. 2017).

Finally, the introduced scoring system provides an easy-tounderstand and clear overview to assess the reliability of potential hybrids. A quick glance at Table 1 immediately shows one hybrid with average support and three cases with insufficient data. This system can be easily applied to other taxonomic groups, resulting in more reliable documentation of interspecific hybrids across the globe.

Availability of data and materials This manuscript is based on a literature review. All data can be found in the reference list.

Code availability Not applicable

Author contribution JO performed the literature search and wrote the manuscript

\section{Declarations}

Conflict of interest The author declares no competing interests.

Open Access This article is licensed under a Creative Commons Attribution 4.0 International License, which permits use, sharing, adaptation, distribution and reproduction in any medium or format, as long as you give appropriate credit to the original author(s) and the source, provide a link to the Creative Commons licence, and indicate if changes were made. The images or other third party material in this article are included in the article's Creative Commons licence, unless indicated otherwise in a credit line to the material. If material is not included in the article's Creative Commons licence and your intended use is not permitted by statutory regulation or exceeds the permitted use, you will need to obtain permission directly from the copyright holder. To view a copy of this licence, visit http://creativecommons.org/licenses/by/4.0/.

\section{References}

Apolinario C, Silveira LF (2019) Hybridism between Cyanocorax chrysops and Cyanocorax cyanopogon (Aves: Corvidae) in Brazil. Zoologia 36:e32138. https://doi.org/10.3897/zoologia.36.e32138

Arnold M (1997) Natural hybridization and evolution. Oxford University Press

Bertelli S (2017) Advances on tinamou phylogeny: an assembled cladistic study of the volant palaeognathous birds. Cladistics 33:351-374. https://doi.org/10.1111/cla.12172

Bertelli S, Porzecanski A (2004) Tinamou (Tinamidae) systematics: a preliminary combined analysis of morphology and molecules. Ornitol Neotrop 15:293-299

Bertelli S, Giannini N, Goloboff P (2002) A phylogeny of the tinamous (Aves: Palaeognathiformes) based on integumentary characters. Syst Biol 51:959-979. https://doi.org/10.1080/ 10635150290102492

Bertelli S, Chiappe L, Mayr G (2014) Phylogenetic interrelationships of living and extinct Tinamidae, volant palaeognathous birds from the New World. Zool J Linnean Soc 172:145-184. https://doi.org/10. 1111/zoj12156 
BirdLife International and Handbook of the Birds of the World (2020) Bird species distribution maps of the world. Version 2020.1. Available at http://datazone.birdlife.org/species/requestdis

Clark W, Galen S, Hull J, Mayo M, Witt C (2017) Contrasting molecular and morphological evidence for the identification of an anomalous Buteo: a cautionary tale for hybrid diagnosis. PeerJ 5:e2850. https:// doi.org/10.7717/peerj.2850

Coster SS, Welsh AB, Costanzo G, Harding SR, Anderson JT, McRae SB, Katzner TE (2018) Genetic analyses reveal cryptic introgression in secretive marsh bird populations. Ecol Evol 8:9870-9879. https:// doi.org/10.1002/ece3.4472

Deck L, Habel J, Curto M, Husemann M, Sturm S, Garitano-Zavala Á, Meimberg H (2016) New microsatellite markers for two sympatric tinamou species, the Ornate Tinamou (Nothoprocta ornata) and Darwin's Nothura (Nothura darwinii). Avian Biol Res 9:139-146. https://doi.org/10.3184/175815515X14503747783157

Dumont S (n.d.) Serge Dumont bird hybrids database. Available at: http:// www.bird-hybrids.com

Fitzpatrick B (2004) Rates of evolution of hybrid inviability in birds and mammals. Evolution 58:1865-1870. https://doi.org/10.1111/j. 0014-3820.2004.tb00471.x

Haines P (2014) Hybrid fairywren at Hart Lagoon, River Murray, South Australia. South Aust Ornithol 39:87-89

Justyn N, Callaghan C, Hill G (2020) Birds rarely hybridize: a citizen science approach to estimating rates of hybridization in the wild. Evolution 74:1216-1223. https://doi.org/10.1111/evo.13943

Knowlton JL, Flaspohler DJ, Mcinerney NCR, Fleischer RC (2014) First record of hybridization in the Hawaiian Honeycreepers: 'I'iwi (Vestiaria coccinea) $\times$ 'Apapane (Himatione sanguinea). Wilson J Ornithol 126:562-568. https://doi.org/10.1676/13-054.1

Maijer S (1996) Distinctive song of highland form maculicollis of the Red-winged Tinamou (Rhynchotus rufescens): evidence for species rank. Auk 113:695-697. https://doi.org/10.2307/4088998

Maxwell LM, Walsh J, Olsen BJ, Kovach AI (2021) Patterns of introgression vary within an avian hybrid zone. BMC Ecol Evol 21:14. https://doi.org/10.1186/s12862-021-01749-1
McCarthy E (2006) Handbook of avian hybrids of the world. Oxford University Press

Monroe Jr. B (1965) A distributional survey of the birds of Honduras. $\mathrm{PhD}$. Thesis, Louisiana State University

Ottenburghs J, Slager D (2020) How common is avian hybridization on an individual level? Evolution 74:1228-1229. https://doi.org/10. 1111/evo.13985

Ottenburghs J, Ydenberg R, van Hooft P, van Wieren S, Prins H (2015) The Avian Hybrids Project: gathering the scientific literature on avian hybridization. Ibis 157:892-894. https://doi.org/10.1111/ibi. 12285

Ottenburghs J, Kraus R, van Hooft P, van Wieren S, Ydenberg R, Prins H (2017) Avian introgression in the genomic era. Avian Res 8:30. https://doi.org/10.1186/s40657-017-0088-Z

Price T, Bouvier M (2002) The evolution of F1 postzygotic incompatibilities in birds. Evolution 56:2083-2089. https://doi.org/10.1111/j. 0014-3820.2002.tb00133.x

Randler C (2004) Frequency of bird hybrids: does detectability make all the difference? J Ornithol 145:123-128. https://doi.org/10.1007/ s10336-004-0022-0

Short L (1975) A zoogeographic analysis of the South American Chaco avifauna. Bull Am Mus Nat Hist 154:163-352

Short L (1976) Notes on a collection of birds from the Paraguayan Chaco. Am Mus Novit 2597:1-16

Sullivan BL, Wood CL, Iliff MJ, Bonney RE, Fink D, Kelling S (2009) eBird: a citizen-based bird observation network in the biological sciences. Biol Conserv 142:2282-2292. https://doi.org/10.1016/j. biocon.2009.05.006

Toews DP, Kramer GR, Jones AW, Brennan CL, Cloud BE, Andersen DE, Lovette IJ, Streby H (2020) Genomic identification of intergeneric hybrids in New World wood-warblers (Aves: Parulidae). Biol J Linn Soc 131:183-191. https://doi.org/10.1093/biolinnean/ blaa085 